\title{
Applying thyroid cancer guidelines: a difficult task
}

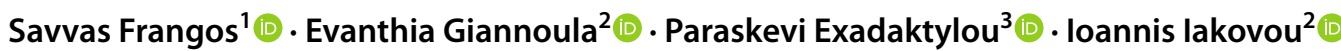

Received: 19 January 2021 / Accepted: 2 April 2021 / Published online: 19 April 2021

(c) Italian Association of Nuclear Medicine and Molecular Imaging 2021

\begin{abstract}
Clinical practice guidelines are a powerful tool in Medicine and provide evidence-based guidance on decision-making regarding diagnosis, management, and treatment. However, the implementation of guidelines can be quite challenging in certain cases. Applying Thyroid Cancer guidelines appears to be a difficult task, particularly regarding the decision for Iodine-131 therapy. The main reason for this, is the great number of available guidelines as well as, their partially controversial suggestions, while often guidelines prove to be rather confusing. All the aforementioned convert clinical practice from pure sciences into art. Our intention with this short commentary is to highlight the difficulties in applying guidelines for thyroid cancer in daily clinical practice and to emphasize the importance of individualized patient-centred approach, to enable the ideal decision making for each patient.
\end{abstract}

Keywords Thyroid cancer · Guidelines · Iodine-131 therapy

Clinical Guidelines are a familiar part of medical practise. The development and implementation of guidelines for the management of Thyroid Cancer are no exception to this.

A remarkably interesting editorial published in 2011, emphasise the fact that even the statements characterized as "evidence based" may not always escape bias caused by the views of their formulators: "recommendations not infrequently suffer from their authors' reading, what they believe instead of believing what they read" [1]. This view is

Savvas Frangos

savvas.frangos@gmail.com

Evanthia Giannoula

eva_giann@hotmail.com

Paraskevi Exadaktylou

voulaexadaktylou@hotmail.com

Ioannis Iakovou

iiakovou@auth.gr

1 Nuclear Medicine Department and Thyroid Cancer Clinic, Bank of Cyprus Oncology Center, 2006 Strovolos, Nicosia, Cyprus

2 Second Academic Department of Nuclear Medicine, Aristotle University of Thessaloniki, University Hospital AHEPA, 54621 Thessaloniki, Greece

3 Third Academic Department of Nuclear Medicine, Aristotle University of Thessaloniki, Papageorgiou General Hospital, 56403 Thessaloniki, Greece confirmed by Huang et al. who argue that the current guidelines suffer from methodological quality [2].

Applying Thyroid Cancer guidelines appears often more complicate than one can expect! Why is that? The problem lies in the great number of guidelines as well as, in their partially controversial suggestions. That is something already recognised by the ATA guidelines published in 2015: "Such differences highlight the importance of clarifying evidence uncertainties with future high-quality clinical research" [3].

A literature search was performed in MEDLINE, EMBASE, SCOPUS and GOOGLE databases looking for published guidelines for the management of patients with malignant thyroid disease. The list of the existing guidelines seems infinite. We identified the most broadly accepted, which consequently affect the prognosis and the quality of life of the majority of patients. Table 1 shows that there is an extremely wide variety of thyroid cancer guidelines among nuclear medicine, endocrinology and surgery societies, which instantly leads us to the conclusion that there is also a wide variety in medical practice.

Moreover, the existing lack of cooperation among different scientific associations is a second way in which guidelines' implementation becomes difficult and problematic. This became clear in the editorial prepared by the EANM in response to a request to endorse the ATA guidelines: "A principal concern underlying our decision is the fact that 
Table 1 List of guidelines

Association/Institution
American Thyroid Association (ATA)

Japan Associations of Endocrine Surgeons

Korean Thyroid Association

European Association of Nuclear Medicine (EANM)

Society of Nuclear Medicine and Molecular Imaging (SNMMI)

American Association of Clinical Endocrinologists (AACE)

American College of Endocrinology (ACE)

American Association of Endocrine Surgeons (AAES)

American Association of Clinical Endocrinologists (AACE)

American College of Endocrinology (ACE)

\section{Italian consensus}

Italian Thyroid Association, Medical Endocrinology Association, Italian Society of Endocrinology, Italian Association of Nuclear Medicine Molecular Imaging, Italian Society of Unified Endocrine Surgery, Italian Society of Anatomic Pathology and Diagnostic Cytology

Spanish Society of Medical Oncology

British Thyroid Association

European Thyroid Association (ETA)

European Society for Medical Oncology (ESMO)

National Comprehensive Cancer Network ( $\mathrm{NCCN})$
Title

2015 American Thyroid Association Management Guidelines for adult patients with thyroid nodules and differentiated thyroid cancer: the American Thyroid Association Guidelines Task Force on thyroid nodules and differentiated thyroid cancer

The revised clinical practice guidelines on the management of thyroid tumors by the Japan Associations of Endocrine Surgeons: core questions and recommendations for treatments of thyroid cancer

The Revised 2016 Korean Thyroid Association Guidelines for thyroid nodules and cancers: differences from the 2015 American Thyroid Association Guidelines

Guidelines for radioiodine therapy of differentiated thyroid cancer

The SNMMI practice guideline for therapy of thyroid disease with $131 \mathrm{I} 3.0$

AACE/AAES MEDICAL/SURGICAL guidelines for clinical practice: management of thyroid carcinoma

American Association of Clinical Endocrinologists and American College of Endocrinology Disease State Commentary: managing thyroid tumors diagnosed as noninvasive follicular thyroid neoplasm with papillary-like nuclear features

Italian consensus on diagnosis and treatment of differentiated thyroid cancer: joint statements of six Italian societies

SEOM clinical guideline thyroid cancer (2019)

Guidelines for the management of thyroid cancer

European consensus for the management of patients with differentiated thyroid carcinoma of the follicular epithelium

2019 European Thyroid Association Guidelines for the treatment and follow-up of advanced radioiodine-refractory thyroid cancer

Thyroid cancer: ESMO clinical practice guidelines for diagnosis, treatment and follow-up

NCCN clinical practice guidelines in Oncology Thyroid carcinoma
Web

https://doi.org/10.1089/thy.2015.0020

https://doi.org/10.3803/EnM.2016.31.3.373

https://doi.org/10.1007/s00259-008-0883-1

https://doi.org/10.2967/jnumed.112.105148

https://pubmed.ncbi.nlm.nih.gov/11430305/ https://pubmed.ncbi.nlm.nih.gov/28920749/

https://doi.org/10.1007/s40618-018-0884-2

https://doi.org/10.1007/s12094-019-02284-8

https://doi.org/10.1111/cen.12515

https://doi.org/10.1530/eje.1.02158

https://doi.org/10.1159/000502229

https://doi.org/10.1093/annonc/mdz400

https://www.nccn.org/professionals/physi cian_gls/pdf/thyroid.pdf the EANM was never consulted during the creation of the Guidelines" [4].

One of our previous works [5] highlights the major differences that arose in decision-making, between three different guidelines, namely ATA 2009, NCCN and EANM, at the same set of patients. The differences for the end decision regarding the ablation indication were significant. Our results revealed that universal applicability of current guidelines is not feasible, which leads to the rhetorical question: "do guidelines mainly apply in the centres that produce them?". 
During the same period, the "new" ATA 2015 guidelines were released. Subsequently, to further explore the issue of "real-world applicability" of DTC guidelines, we retrospectively compared indications for ablation using ATA 2015 versus ATA 2009. Using either of those guidelines to determine indications for ablation is a somewhat subjective process, "art rather than science" [6]. Commenting on our paper, Verburg et al. wrote an editorial, wondering whether ATA 2015 guidelines are an exact science or a dark art, concluding that they "can only encourage you, readers and colleagues when in doubt, to refer to this document, (the EANM guidelines) rather than the ATA 2015 guidelines" [7]. By this statement, it also gets clear that every Association tries to "promote" their own guidelines.

To overcome the obstacle of the lack of cooperation, experts from the ATA, the EANM, the SNMMI, and the ETA hosted two meetings to address some of the differences in opinion and controversies associated with the therapeutic uses of Iodine-131 in differentiated thyroid cancer. They chose Martinique, a small island in the pacific, to host a two-day interactive meeting each time. The result of the first meeting is the formulation of nine principles (The Martinique Principles Table 2). Although this "white" paper [8] is not guidelines, it sets the principles of scientific thinking regarding the treatment of Thyroid Cancer especially the Iodine-131 therapy.

In our opinion, there are, two fundamental statements reported in this paper: "It is surprising that more than 70 years after the first use of Iodine-131 there are still controversies regarding the therapeutic use of Iodine-131 therapy" and "Major gaps in knowledge and evidence regarding optimal use of Iodine-131 therapy should be addressed with properly designed prospective studies."

The significant breakthrough of this paper is summarized in the importance of individualized patient-centered approach of thyroid cancer patients, which in addition takes into consideration patients' wishes, objections, hopes, and fears.

The Martinique Principle 3 underlines the need to distinguish between patients with the persistent disease who require aggressive treatment strategies and those without evidence of persistent disease who are candidates for "watchful waiting", remnant ablation, or adjuvant treatment. The Martinique Principles makes it clear that all thyroid cancer patients are potential candidates for treatment with Iodine-131. Unfortunately, the simplification of tumor size as an indication of non ablation, mentioned in most of the guidelines, is not commented in this Principle even leading to "wrong" decisions.

In Martinique Principle 5, the consideration and evaluation of multiple factors introduce the need to acknowledge the existing local conditions such as the expertise of the operating surgeon. In one of our previous works [5] a total number of 90 surgeons operated on 336 patients. The principle "think globally act locally" should be applied when we are dealing with thyroid cancer patients.

The main concerns of administrating Iodine-131 therapy are the administrated activity, the intended result, and the incidence of adverse effects. Unfortunately, there are no universal answers to these questions. As a matter of fact, Iodine-131 therapy decreases the number of relapses [9]. While it is also true that the incidence of

Table 2 The Martinique principles

Principles of the Martinique meeting [8]

1 "Advancing our understanding of optimal thyroid cancer management requires a commitment by clinicians, researchers, patients, and organizations to engage in proactive, purposeful, and inclusive interdisciplinary cooperation"

2 "The goal of 131I therapy should be characterized as remnant ablation, adjuvant treatment, or treatment of known disease using standardized definitions"

3 "Assessment of postoperative disease status is required to optimize proper patient selection for 131I therapy (remnant ablation, adjuvant treatment, or treatment of known disease)"

4 "Postoperative disease status evaluations should be standardized and integrated into routine clinical care"

5 "Optimal patient selection for 131I adjuvant treatment requires consideration and evaluation of multiple factors beyond postoperative disease status and risk stratification"

6 "The optimal administered 131I activity for adjuvant treatment cannot be definitely determined from the published literature. Until definitive data are available, selection of the administered activity for adjuvant treatment should be based on multidisciplinary team management recommendations"

7 "Characteristics used to classify patients as 131I refractory should be used to risk stratify patients with regard to the likelihood that a tumor will respond to 131I therapy and not necessarily as definitive criteria to mandate whether 131I therapy should be recommended"

8 "131I-refractory criteria will continue to evolve as (i) additional studies address important limitations and technical issues confounding the current literature, (ii) techniques for radioactive iodine imaging are optimized and standardized, and (iii) re-differentiation therapies enhance the effectiveness of 131I therapy"

9 "Major gaps in knowledge and evidence regarding optimal use of 131I therapy should be addressed with properly designed prospective studies" 
microcarcinomas is constantly increasing [10]. This group of patients are characterized by a lower risk of recurrence. The impasse reached owing to these controversies is expressed by Principle 6: "Until the results of prospective multicentre studies cantering on relevant outcomes of adjuvant postoperative Iodine-131 treatment, including disease-specific survival and disease-free survival as well as the incidence of side effects, are available, the activity to be prescribed for adjuvant treatment of Differentiated Thyroid Carcinoma remains a question best answered on an individual basis in a multidisciplinary setting".

Guidelines are pathways set up to define a course of action. They are unarguably useful tools that help clinicians to provide appropriate health care to patients. By no means they can substitute clinician's experience and critical view. Moreover, we should bear in mind that a onesize-fits-all approach to patient care is not untenable. Not every clinical condition can fit into a clean category nor a specific therapy option can result in an expected outcome.

Radioiodine therapy for differentiated thyroid cancer comprises one of the first targeted molecular therapies in cancer treatment and although it has proven its clinical efficacy since its first application in the 1940s [11], it remains unclear in some cases whether to treat or not. Achieving zero harm, by avoiding overtreatment or undertreatment, is a daunting challenge. Martinique meeting is a promising step that fosters cooperation between all thyroid cancer specialists, so as a consensual thyroid cancer treatment approach to be accomplished.

Even though we strongly believe that guidelines are useful tools the Question still remains: Where should guidelines apply exactly? Undoubtedly in "Utopia": a community with the privilege of highly desirable or nearperfect qualities [12].

In this Platonic city of "Kallipolis" [13] the most experience Surgeons coexist with ultra-sonographers, who can see more than the details, pathologists with the best eyes, patients without individual problems and of course with the best Thyroid Cancer Specialists.

Availability of data and material (data transparency) This is a review article, and all reviewed studies are referenced.

\section{Declarations}

\section{Conflict of interest None.}

Ethical approval This article does not contain any studies with human or animal subjects performed by any of the authors.

\section{References}

1. Dietlein M, Verburg FA, Luster M, Reiners C, Pitoia F, Schicha $H$ (2011) One should not just read what one believes: the nearly irresolvable issue of producing truly objective, evidence-based guidelines for the management of differentiated thyroid cancer. Eur J Nucl Med Mol Imaging 38(5):793-798. https://doi.org/ 10.1007/s00259-011-1728-x

2. Huang TW, Lai JH, Wu MY, Chen SL, Wu CH, Tam KW (2013) Systematic review of clinical practice guidelines in the diagnosis and management of thyroid nodules and cancer. BMC Med 11:191. https://doi.org/10.1186/1741-7015-11-191

3. Haugen BR, Alexander EK, Bible KC, Doherty GM, Mandel SJ, Nikiforov YE et al (2016) 2015 American thyroid association management guidelines for adult patients with thyroid nodules and differentiated thyroid cancer: the American thyroid association guidelines task force on thyroid nodules and differentiated thyroid cancer. Thyroid 26(1):1-133. https://doi.org/10.1089/ thy. 2015.0020

4. Verburg FA, Aktolun C, Chiti A, Frangos S, Giovanella L, Hoffmann $M$ et al (2016) Why the European association of nuclear medicine has declined to endorse the 2015 American thyroid association management guidelines for adult patients with thyroid nodules and differentiated thyroid cancer. Eur J Nucl Med Mol Imaging 43(6):1001-1005. https://doi.org/10.1007/ s00259-016-3327-3

5. Frangos S, Iakovou IP, Marlowe RJ, Eftychiou N, Patsali L, Vanezi A et al (2015) Difficulties in deciding whether to ablate patients with putatively "low-intermediate-risk" differentiated thyroid carcinoma: do guidelines mainly apply in the centres that produce them? Results of a retrospective, two-centre quality assurance study. Eur J Nucl Med Mol Imaging 42(13):20452055. https://doi.org/10.1007/s00259-015-3124-4

6. Frangos S, Iakovou IP, Marlowe RJ, Eftychiou N, Patsali L, Vanezi A et al (2017) Acknowledging gray areas: 2015 vs. 2009 American thyroid association differentiated thyroid cancer guidelines on ablating putatively low-intermediate-risk patients. Eur J Nucl Med Mol Imaging 44(2):185-189. https://doi.org/10. 1007/s00259-016-3495-1

7. Verburg FA, Luster M, Giovanella L (2017) Adjuvant postoperative I-131 therapy in differentiated thyroid carcinoma: are the 2015 ATA guidelines an exact science or a dark art? Eur J Nucl Med Mol Imaging 44(2):183-184. https://doi.org/10.1007/ s00259-016-3526-y

8. Tuttle RM, Ahuja S, Avram AM, Bernet VJ, Bourguet P, Daniels GH et al (2019) Controversies, consensus, and collaboration in the use of ${ }^{131}$ I therapy in differentiated thyroid cancer: a joint statement from the American thyroid association, the European association of nuclear medicine, the society of nuclear medicine and molecular imaging, and the european thyroid association. Thyroid 29(4):461-470. https://doi.org/10.1089/thy.2018.0597

9. Krajewska J, Jarzab M, Kukulska A et al (2019) Postoperative radioiodine treatment within 9 months from diagnosis significantly reduces the risk of relapse in low-risk differentiated thyroid carcinoma. Nucl Med Mol Imaging 53:320-327. https:// doi.org/10.1007/s13139-019-00608-8

10. Hughes DT, Haymart MR, Miller BS, Gauger PG, Doherty GM (2011) The most commonly occurring papillary thyroid cancer in the United States is now a microcarcinoma in a patient older than 45 years. Thyroid 21(3):231-236. https://doi.org/10.1089/ thy. 2010.0137

11. Seidlin S (1946) Radioactive iodine therapy. Effect on functioning metastases of adenocarcinoma of the thyroid. JAMA 132:838-847 
12. More, Thomas [Utopia:] De optimo reip. statu, deque nova insula Utopia, libellus vere aureus. -Epigrammata. - Desiderius ERASMUS. Epigrammata. Johann Froben, Basel, NovemberDecember 1518

13. Platon, Politeia, E, 473 c11-e5. Platonis opera. I-V. Burnet J (ed) 1900-07. Clarendon Press, Oxford
Publisher's Note Springer Nature remains neutral with regard to jurisdictional claims in published maps and institutional affiliations. 